$\mathrm{DOE}_{1} / \mathrm{ER} / 13913--5$

DE93 010083

\title{
Evolution of Flow Disturbances \\ in \\ Cocurrent Gas-Liquid Flows
}

Progress Report

for Period 11/1/91-10/31/92

\author{
Mark J. McCready \\ Department of Chemical Engineering \\ University of Notre Dame \\ Notre Dame, Indiana 46556
}

October, 1992

Prepared for

The U. S. Department of Energy

Agreement no. DE-FG02-88ER13913

\section{Notice}

This report was prepared as an account of work sponsored by the United States Government. Neither the United States nor the Department of Energy, nor any of their employees, nor any of their contractors, subcontractors, or their employees, makes any warranty, express or implied, or assumes any legal liability or any responsibility for the accuracy, completeness, or usefulness of any information, apparatus, product or process disclosed or represents that its use would not infringe privately-owned rights. 
Abstract

Studies of interfacial waves in horizontal gas-liquid flows, close to neutral stability, suggest that the rate of evolution of the interface may be linked to nonlinear interactions between the fundamental mode and the subharmonic -- even if the subharmonic is linearly stable. The rate of evolution increases as the subharmonic becomes more unstable. A comparison of linear stability techniques used to predict the initial behavior of waves reveals similar predictions of growth rates and almost identical speeds between a two layer laminar Orr-Sommerfeld theory and an OrrSommerfeld theory where the effect of the (turbulent) gas flow enters as boundary conditions on the liquid layer. However, there is disagreement at small wavenumbers as to the point at which the growth curve crosses 0 . This is a significant problem because longwave disturbances, in our case roll waves, form by growth of (initially) small amplitude waves that have frequencies which are 0.5 to $1 \mathrm{~Hz}$, which is in the range where the two theories disagree about the sign of the growth rate. While nonlinear effects are probably involved in the formation of the peak (at least while its amplitude is small), the linear growth rate must play an important role when the amplitude is small.

Work will continue on both of these areas in the upcoming year. 


\section{Table of Contents}

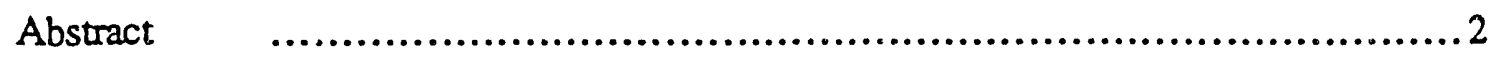

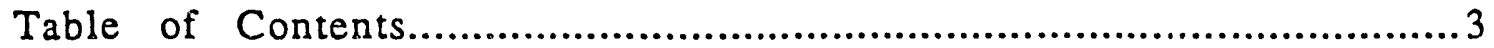

Description of Research ........................................................... 4

a. Wave evolution close to neutral stability ..........................4

b. Examination of linear stability theories for wave formation and regime

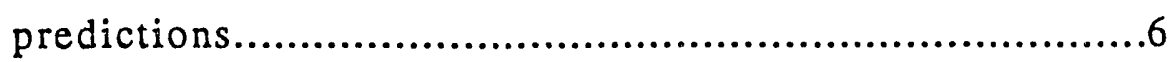

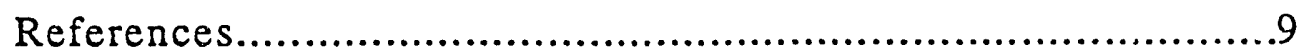

Publications resulting from this grant (last 12 months) ................................ 10

Presentations resulting from this grant (last 12 months)........................................ 10

Effort devoted to this project by the Principal Investigator..............................11

Funds remaining from last year............................................................11

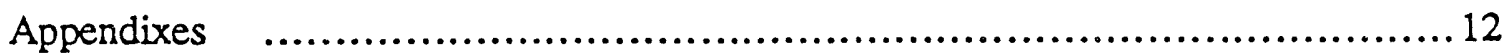

Biographical summary of the Principal Investigator .................12 


\section{Description of Research}

During the past 12 months, we have continued our studies of waves both at conditions close to neutral stability, where we are attempting to determine the factors that control the rate at which waves evolve (i.e. slow change of shape) with distance, and at more severe conditions where we are examining how different approximations made in linear theories affect the predictions of wave formation and flow regime transitions. We are using roll wave formation as a model disturbance for the flow regime transition work.

a. Wave evolution close te neutral stability

By measuring interfacial wave tracings at two locations in the flow direction, we have previously determined that even very close to neutral stability, where the amplitude saturates with distance and the waves remain largely sinuous, individual waves continue to slowly change shape with evolution rates that depend on flow parameters. An example series of data was given in this progress report in 1990 and also recently published (Sangalli et al. 1992). The fundamental mode, along with one or more overtones is predicted to reach a steady state from our weakly nonlinear theory. If the steady state is stable, the theory suggests that waves would not continue to oscillate or evolve with distance. We examined the stability of the steady state to side bands, and found that it is predicted to be stable (Jurman et al. 1992). In Jurman et al. (1992) we described how the fundamental can be lead to the formation of a subharmonic. However, none of these results explained why waves have different evolution rates when subharmonics were not present. 
We have continued these studies this year. By considering just the two mode system between the fundarnental and the first subharmonic, we can derive a two mode system of equations of the form

$$
\begin{aligned}
& \dot{A}_{1}=d_{1} A_{1}+P_{1} A_{1 / 2}^{2}+D_{1}\left|A_{1}\right|^{2} A_{1}+D_{2}\left|A_{1 / 2}\right|^{2} A_{1} \\
& \dot{A}_{1 / 2}=d_{1 / 2} A_{1}+P_{3} A_{1 / 2}^{*} A_{1}+D_{5}\left|A_{1}\right|^{2} A_{1 / 2}+D_{6}\left|A_{1 / 2}\right|^{2} A_{1 / 2}
\end{aligned}
$$

where $A_{i}$ is the complex wave amplitude ${ }^{1}$. In these equations, $P_{1}$ and $P_{3}$ are coefficients from a weakly viscous quadratic theory (Jurman et al. 1992), $D_{1}, D_{2}$ and $D_{3}$ come from the center manifold projection of the (stable) overtones of the fundamental (The direct contributions from cubic theory are much smaller) and $D_{6}$ requires knowledge of the cubic self-interaction. Because $D_{6}$ must come directly from cubic interactions, the coefficient $D_{6}$ is much smaller than the others and is not known as accurately.

Equations (1) can be converted into the "double - Hopf" normal form. (Guckenheimer and Holmes, 1983),

$$
\begin{aligned}
& \dot{r_{1}}=\mu_{1} r_{1}+a_{11} r_{1}^{3}+a_{12} r_{1} r_{2}^{2} \\
& \dot{r_{2}}=\mu_{2} r_{2}+a_{21} r_{1}^{2} r_{2}+a_{22} 5^{3}
\end{aligned}
$$

In (2), the coefficients, $a_{11}, a_{12}, a_{21}$ are positive. The coefficient $a_{22}$ is also positive, but close to 0. The unfoldings given in Guckenheimer and Holmes (1983), show that both steady and oscillatory solutions are possible and that the rate of oscillation increases as the growth rate of the subharmonic gets less negative and then becomes positive. Our data are consistent with this result as the faster oscillation rate is occurring as the subharmonic becomes more unstable.

\footnotetext{
${ }^{1}$ Note also that these are written for the temporal approximation to a spatially varying system. Our plan is to address the problem in terms of explicit spatial variations, if the temporal analysis indicates that this is necessary.
} 
This agreement notwithstanding, this must be considered a preliminary result for several reasons. First, the value of the coefficient $D_{6}$ is critical and we need to verify the validity of some simplifications that were necessary to get the result from cubic theory. Second, the analysis is done for temporally varying disturbances and the real system varies spatially with a continual effect of inlet noise. Third, the system consists of a band of unstable modes and we have done theory for only a single fundamental and a single subharmonic. Even if all if the unstable fundamental modes are stable to side-band interactions, it is not clear if the continuous system behaves the same as a set of discrete modes. In the upcoming year, we will address these concerns.

\section{b. Examination of linear stability theories for wave formation and regime predictions}

There are about 100 papers that address the linear stability of two-fluid flows in systems such as large bodies of water (e.g. Kawai, 1979; Gastel et al., 1985), laminar fluids in channels (e.g. Yih, 1967; Renardy, 1989), turbulent gas-liquid flows (Craik, 1966; Hanratty, 1983; Andritsos and Hanratty, 1987). In addition, linear theories have been used to predict the instability of the stratified regime to slugs or annular flow (Taitel and Dukler, 1976; Lin and Hanratty, 1986; Barnea, 1991; Crowley, Wallis \& J. J. Barry, 1992; Brauner and Maron, 1991). From the standpoint of application to multiphase flows, perusal of this literature reveals three important points. First, the studies that predict flow regimes are based on one-dimensional momentum equations rather that than Orr-Sommerfeld equations are therefore are not capable of accurate predictions of the stability point, and secondly, there has been little evaluation of the applicability of various approximations that are made (e.g. use of turbulent stress correlations as boundary conditions) to deal with turbulent flows and third, in the multiphase flow literature (although not the other papers) most of the papers have used approximate solutions (e.g. long wavelength) that are not necessarily valid in the range of interest. 
Our work this year has included comparison of the predictions of some of these theories. In figure 1, the growth curves for gas-liquid channel flows at a series of conditions at increasing gas Reynolds number are shown. The two-layer laminar "exact" Orr-Sommerfeld solution is compared to a solution for a laminar liquid with gas flow effects entering through the interfacial boundary conditions. Correlations for turbulent flow over solid wavy surfaces (Abrams, 1984) are used to determine the pressure and shear variations. The predictions of the one-dimensional macroscopic momentum balance analysis are also shown for two conditions. The liquid depth and interfacial stress are the same for all three cases being obtained from laminar profile in both phases. A tau-spectral algorithm is used to solve the Orr-Sommerfeld eigenvalue problems. It is seen that the predicted growth rate agrees reasonably closely for the two Orr-Sommerfeld techniques. There is shift in the range of unstable wavenumbers and the turbulent stress method predicts a higher growth rate. Figure 2 shows the corresponding speeds which are essentially the same for the two Orr-Sommerfeld predictions. The one-dimensional momentum equation approach, does not work at all. It is noted that it would show positive growth rates at conditions more severe than those shown in this figure, but it can never capture the correct wavenumber dependence. The reasonably good agreement between the Orr-Sommerfeld approaches is encouraging because the real system would not be laminar for most of the gas- Reynolds numbers shown here ${ }^{2}$, (thus the two-layer laminar predictions could be in doubt) and while the use of turbulent stress correlations has shown some agreement with experiments, there is some doubt about the range of applicability. In the future, we intend to incorporate different velocity profiles into our two-layer calculations because Gastel et al. (1985) has demonstrated significant effects for unbounded two-layer flows. The predictions will be verified by measured wavelengths, growth rates and speeds.

\footnotetext{
2 and for most systems of practical interest.
} 

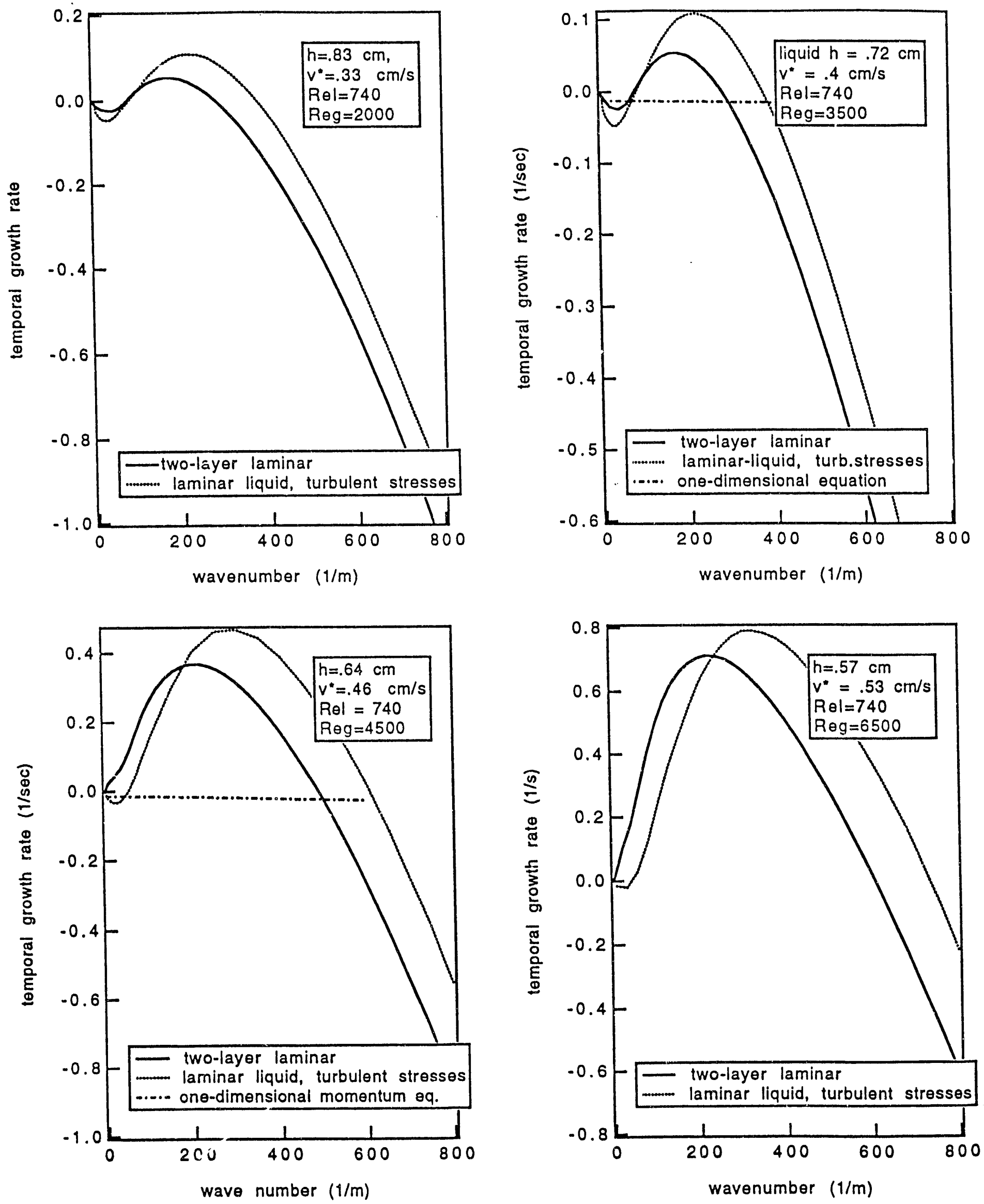

Figure 1. Growth curves for air-water channel flow using three different linear stability methods. 

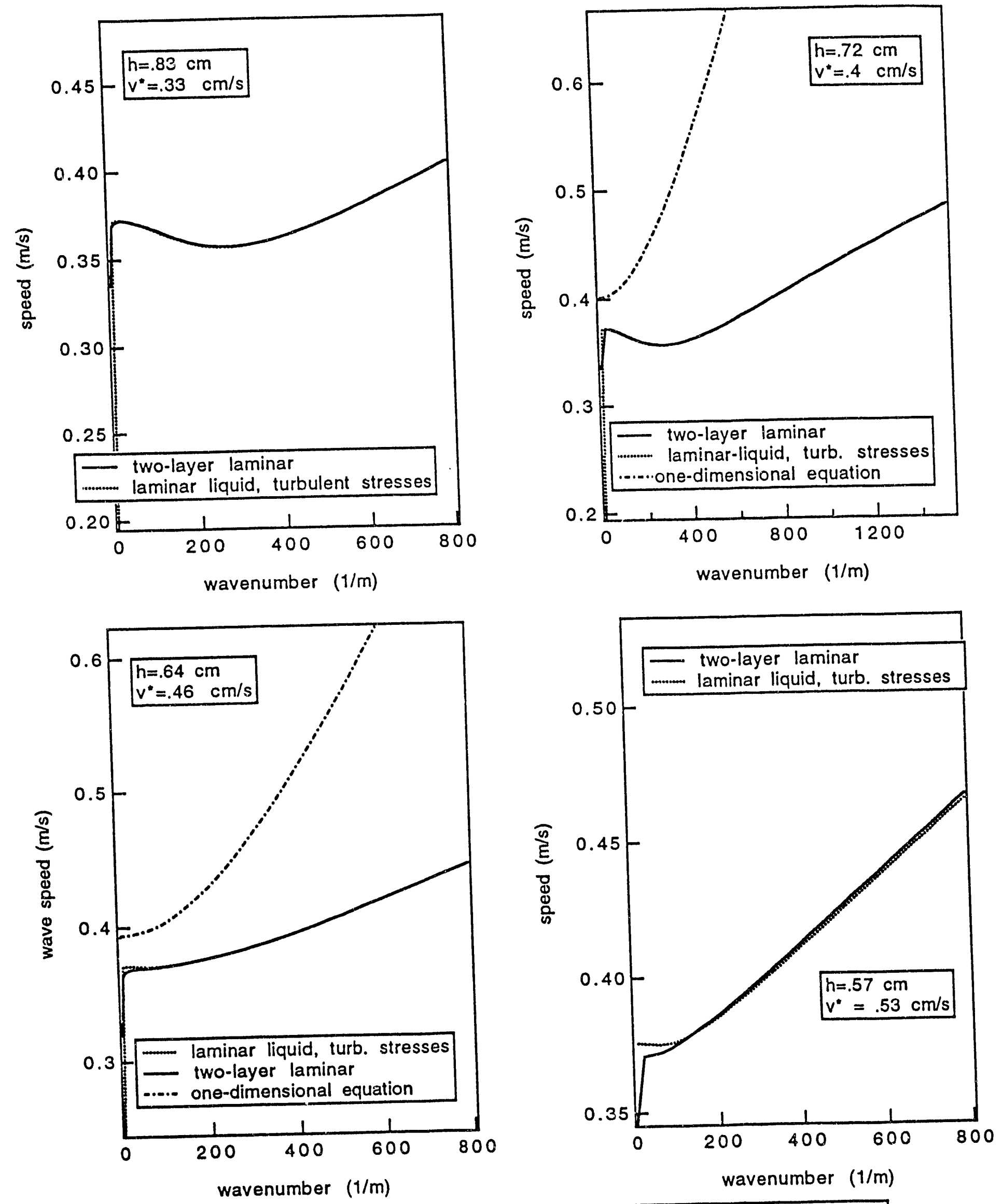

Figure 2. Comparison of the predicted wa re speeds using three different linear stability methods. 
While the methods above may be capable of adequate predictions of the initial wavelength, speed and growth rate, the problem of interpreting data for the formation of secondary disturbances is not solved. Figure 3 shows a wave spectrum which contains a secondary peak (the main peak, which is very broad, is in the $10-30 \mathrm{~Hz}$ range) that we have previously identified (Bruno and McCready, 1988) as a precursor to roll waves, along with the two Orr-Sommerfeld predictions for the growth rates. In that study, we used two different approximations to linear stability theory (i.e. long wavelength, boundary-layer type and short wavelength, Orr-Sommerfeld based), which required interpolation between the limits, to determine the growth curve. At the time, we attributed the emergence of a secondary low frequency precursor peak in the wave spectrum to a peak in the growth rate obtained from the longwave stability analysis. However, the numerical solution to the linear stability problem demonstrates that there are not two different peaks. This causes (or reveals) two problems. First, the linear growth curve provides no clue as to why a sharp peak at .5 to $1 \mathrm{~Hz}$ forms at all. Second, it points out the need for accurate prediction of the linear growth rate in this region. Is this roll wave precursor peak stable or unstable ?? Figure 3 shows that we cannot currently answer this question.

It is quite possible that nonlinear effects are responsible for the formation of the precursor peak. However, knowledge of the growth range in this frequency range is essential for any quantitative predictions. In the upcoming year we will examine the roll wave formation problem with addition experiments, which will involve measuring the speed of the precursor peak as well as the waves near the peak in the growth curve. If the speed of the peak and the precursor mode are close, energy transfer is facilitated. Numerical simulations of the spectrum will be also done using integrations of the mode equations that wu have derived previously (Jurman et al. 1992) to try and determine if combined nonlinear effects can lead to the observed focusing. 


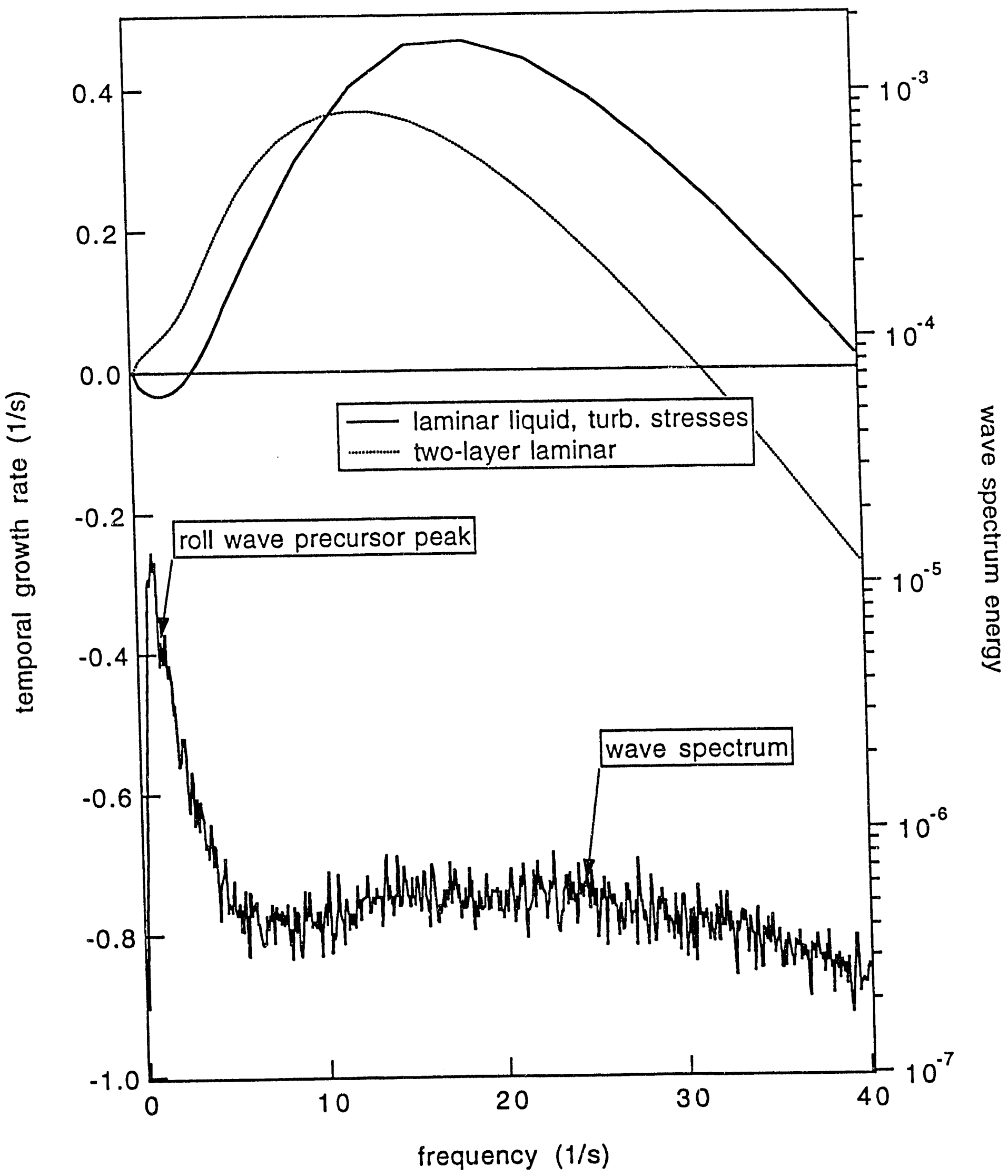

Figure 3. Comparison of linear growth rates and wave spectrum measured 5 meters from the inlet. A roll wave precursor peak is seen to occur at a frequency where the two linear theories disagree about the sign of the growth curve. 


\section{References}

Abrams, J. 1984 Turbulent flow over small amplitude solid waves. Ph. D. Thesis, Department of Chemical Engineering, University of nlinois, Urbana.

Andritsos, N. and T. J. Hanratty (1987) Interfacial instabilities for horizontal gas-liquid flows in pipelines. Int. J.Mult. Flow 13, 583-603.

Andreussi, P., Asali, J. C. \& Hanratty, T. J. (1985) Iniciation of roll waves in gas-liquid flows. AIChE J. 31, 119-126.

Barnea, D. (1991) On the effect of viscosity on stability of stratified gas-liquid flow-application to flow pattern transition at various pipe inclinations. Chem. Eng. Sci. 46, 2123-2131.

Brauner, N. \& D. M. Maron (1991) Analysis of stratified/nonstratified transitional boundaries in horizontal gas-liquid flows. Chem. Eng. Sci. 46, 1849-1859.

Bruno, K. \& McCready, M. J. 1988 Origin of roll waves in gas-liquid flows. AlChE J. 34 14311440.

Crowley, C. J., G. B. Wallis and J. J. Barry (1992) Validation of a one-dimensional wave model for the stratified to slug flow regime transition, with consequences for wave growth and slug frequency. to appear Int. J. Mult. Flow .

Craik, A. D. D. 1966 Wind-generated waves in thin liquid films. J. Fluid Mech. 26, 369-392.

Gastel, K. van, Janssen, P. A. E. M. \& Komen G. J. 1985 On phase velocity and growth rate of wind-induced gravity-capillary waves. J. Fluid Mech. 161 199-216.

Guckenheimer, J. and P. Holmes. 1983 Nonlinear Oscillations, Dynamical Systems ,and Bifurcations of Vector Fields. Springer.

Hanratty, T. J. 1983 Interfacial instabilities caused by air flow over a thin liquid layer. in:Waves on Fluid Interfaces, (Edited by Meyer, R. E.), Academic Press, New York, 221-259.

Jurnan, L. A., Deutsch, S. E. and M. J. McCready (1992) Interfacial mode interactions in horizontal gas-liquid flows J. Fluid Mech. 238, 187-219.

Kawai, S. 1979 Generation of initial wavelets by instability of a coupled shear flow and their evolution to wind waves. J. Fluid Mech. 93, 661-703.

Lin, P. Y. and T. J. Hanratty (1986) Int. J. Multiphase Flow 12, p. 79.

Renardy, Y. (1989) Weakly-nonlinear behavior of periodic disturbances in two-layer CouettePoiseuille flow. Phys. Fluids A 1, 1666-1676.

Sangalli, M., Th. Prokopiou, M. J. McCready and H. -C. Chang, (1992) Observed transitions in two-phase stratified gas-liquid flow, Chem. Eng. Sci., 47, 3289-3296.

Taitel Y. and Dukler, A. E. (1976) AIChE J. 22, p. 47. 
Yih, C.-S. (1967) Instability due to viscosity stratitication. J. Fluid Mech. 27, 337-352.

\section{Publications resulting from this grant (last 12 months)}

L. A. Jurman, S. E. Deutsch, and M. J. McCready "Interfacial mode interactions in horizontal gas-liquid flows", J. Fluid Mech. 238, pp 187-219, 1992.

M. Sangalli, Th. Prokopiou, M. J. McCready and H. -C. Chang, "Observed transitions in two-phase stratified gas-liquid tlow", Chem. Eng. Sci., 47, pp 3289-3296, 1992.

\section{Presentations resulting from this grant (last 12 months)}

"Regular and irregular disturbances in gas-liquid flows", Department of Chemical Engineering, University of Virginia, April 23, 1992.

"Phenomenological understanding of gas-liquid stratified flows", Invited presentation at the Third International Workshop on Two-Phase Flow Fundamentals" Imperial College, London, June 15-19, 1992 (with T. J. Hanratty).

M. Sangalli, Th. Prokopiou, M. J. McCready \& H. -C. Chang,"Transitions in stratified two-phase flows: theory and experiments", Conference: Instabilities in multiphase flow, Rouen France, May 11-13, 1992.

M. Sangalli, Th. Prokopiou, M. J. McCready and H. -C. Chang, "Observed transitions in two-phase stratified gas-liquid flow", 1st International conference on gas-liquid and gas-liquid-solid reactor engineering, Columbus OH, September 13-16, 1992. 


\section{Effort devoted to this project by the Principal Investigator}

During the academic year, the P.I. is engaged in research activities approximately $60 \%$ of the time, teaching activities $30 \%$ of the time and about $10 \%$ of his time is devoted to administrative activities. The work related to the present grant comprises about $60 \%$ of his research activities so that he spends slightly over $33 \%$ of his time on the current project. In the summer months, essentially all of his time is spent on research activities so that about $60 \%$ of his time is allotted to the current project. This allotment of time is expected to continue.

\section{Funds remaining from last year}

From the current rate of expenditure and outstanding obligations, it is expected that no funds will remain at the end of the present year. 


\section{Appendixes}

Biographical summary of the Principal Investigator

Mark J. McCready

Associate Professor

Department of Chemical Engineering

University of Notre Dame

A. Education

University of Delaware, B.Ch.E. in Chemical Engineering

1979.

University of Illinois, M.S. in Chemical Engineering

University of Ilinois, Ph.D. in Chemical Engineering

B. Eellowships and Honors

National Merit Scholarship

Chevron Company Scholarship

$1975-1979$

General Electric Company Fellowship

1978

Exxon Educational Foundation Fellowship

1979

FMC Corporation Fellowship

1980

University of mlinois Graduate Fellowship

1981

Marathon Oil Company Scholarship

1982

1983

C. Professional Experience

June - August 1979

Assistant Engineer, Hoffman-LaRoche, Nutley, NJ.

Fall 1983

Instructor, Department of Chemical Engineering, University of Dlinois

August, 1984 -

Assistant Professor, Department of Chemical Engineering, August, 1989 University of Notre Dame

August, 1989-

Associate Professor, Department of Chemical Engineering, University of Notre Dame

D. Professional Societies

American Physical Society, American Chemical Society, Sigma Xi, American Institute of Chemical Engineers, American Society for Engineering Education 
E. Principal Research Interests

fluid mechanics of multiphase flows, turbulent transport, interfacial waves, separation processes, fluid mechanics of supercritical fluids.

F. Selected List of Services to the University

a) University

Jesse Jones Research Equipment Grant Advisory Panel

Representative to the Midwest Universities

Energy Consortium

Appointed representative to UCCIS

Research computing advisory committee

$1988-1990$

1990 -

$1990-1992$

1990 -

b) College

Facilities and Services Committee

Computer Advisory Committee

(Chairman)

$1984-1989$

1990 -

$1990-1991$

c) Department

Graduate Recruiting

(Chairman)

(Chairman)

$1984-1990$

$1985-1987$

$1989-1990$

Graduate Studies and Research

$1984-1991$

Academic Grievances-Appeals Committee

$1984-1985$

Committee on Promotions

1989 -

Undergraduate studies (Chairman)

1991 -

G. Publications

a) Refereed journals

\section{Research}

1. M. J. McCready, J. M. Schultz, J. S. Lin, and R. W. Hendricks, "Effect of crystallization time on the properties of melt-crystallized linear polyethylene", Journal of Polymer Science: Polymer Physics Edition, 17, 725-740, 1979.

2. J. S. Lin, R. W. Hendricks, J. M. Schultz and M. J. McCready, "Absolute integrated SAXS measurements during crystallization of linear polyethylene", Journal of Polymer Science: Polymer Physics Edition, 20, p 1365-1369, 1982.

3. M. J. McCready and T. J. Hanratty, "Concentration flucruations close to a gas-liquid interface", AIChE Journal, 30, pp 816-817, 1984.

4. M. J. McCready and T. J. Hanratty, "Effect of air shear on gas absorption by a liquid film", AIChE Journal, 31, pp 2066-2074, 1985.

5. M. J. McCready, E. Vassiliadou and T. J. Hanratty, "Computer simulation of turbulent mass transfer at a mobile interface", AIChE Journal, 32, pp 1108-1115, 1986. 
6. M. J. McCready, "Spectral behavior of capillary waves in gas-liquid flows", The Physics of Fluids, 29, pp 2836-2842, 1986.

7. D. D. Back and M. J. McCready,"Effect of small wavelength waves on gas transfer across the ocean surface", Joumal of Geophysical Research, 23, C.5, pp 5143-5152, 1988.

8. K. Bruno and M. J. McCready, "Origin of roll waves in gas-liquid flows", AIChE Journal 34, pp 1431-1440, 1988.

9. D. T. Leighton and M. J. McCready, "Shear enhanced transport in oscillatory liquid membranes", AIChE Journal 34, pp 1709-1712, 1988.

10. D. D. Back and M. J. McCready, "Theoretical study of interfacial mass transport in gasliquid flows", AIChE Journal 34, pp 1789-1802, 1988.

11. L. A. Jurman and M. J. McCready, "Study of waves on thin liquid films sheared by turbulent gas flows", Physics of Fluids A 1, pp 522-536, 1989.

12. L. A. Jurman, K. Bruno and M. J. McCready, "Periodic and solitary waves on thin, horizontal, gas-sheared liquid films", International Journal of Multiphase Flow 15 ,pp 371$384,1989$.

13. K. Bruno and M. J. McCready, "Study of the processes which control the interfacial wave spectrum in separated gas-liquid flows", Intemational Joumal of Multiphase Flow 15, pp $531-552,1989$.

14. A. Chandhok, N. Voorhies, M. J. McCready and D. T. Leighton, "Measurement of transport enhancement in oscillatory liquid membranes", AIChE Journal, 36, pp 1259 $1262,1990$.

15. M. J. McCready, M. Gupta, L. A. Jurman and K. Bruno, "Properties of small-scale waves in sheared gas-liquid flows", in Air-Water Mass Transfer ed.Wilhelms \&: Gulliver pp 116-125. ACSE 1991.

16. C. -A. Peng, L. A. Jurman, and M. J. McCready "Formation of solitary waves on gassheared liquid layers", International Journal of Multiphase Flow, 17, pp 767-782, 1991.

17. L. A. Jurman, S. E. Deutsch, and M. J. McCready "Interfacial mode interactions in horizontal gas-liquid flows", J. Fluid Mech. 238, pp 187-219, 1992.

18. J. A. Helwick, P. O. Dillon and M. J. McCready, "Time varying behavior of cocurrent gas-liquid flows in packed beds", Chem. Eng. Sci., 47, pp 3249-3256, 1992.

19. M. Sangalli, Th. Prokopiou, M. J. McCready and H. -C. Chang, "Observed transitions in two-phase stratified gas-liquid flow", Chem. Eng. Sci., 47, pp 3289-3296, 1992. 
submitted:

T. Prokopiou, M. J. McCready and H. -C. Chang "Wave transitions on horizontal gassheared liquid films", submitted to: J. Fluid Mech., January, 1991.

T. J. Hanratty and M. J. McCready, "Phenomenological understanding of gas-liquid stratified flows", submitted to Multiphase Science and Technology, April, 1992 (text of invited presentation at the Third International Workshop on Two-Phase Flow Fundamentals" Imperial College, London, June 15-19, 1992)

\section{Education}

M. J. McCready, and D. T. Leighton, " $\dot{s}$ course in transport phenomena", Chemical Engineering Education. 21, p 174-177, 1987.

M. J. McCready, "An alternative to the process design course", Chemical Engineering Education, 23, p 82-85, 1989.

b) Other publications

M. J. McCready and T. J. Hanratty, "A comparison of turbulent mass transfer at gas-liquid and solid-liquid interfaces", pp 283-292 in W. Brutsaert and G. H. Jirka eds., Gas Transfer at Water Surfaces, D. Reidel Publishing Co., 1984.

M. J. McCready, L. A. Jurman, C. -A. Peng and S. E. Deutsch, "Evolution of interfacial disturbances in horizontal gas-liquid flows", pp 129-136, in Proceedings of the Eight Symposium on Energy Engineering Sciences. (1990).

\section{H. Invited Seminars and Presentations}

"Interfacial behavior in gas-liquid flows", Department of Chemical Engineering, Purdue University, October 20,1988.

"Interfacial behavior in separated gas-liquid flows", Department of Chemical Engineering, University of Houston, February 3, 1989.

"Interfacial waves in cocurrent gas-liquid flows", Amoco Research Center, July 31, 1989.

"Disturbance propagation in open flows", Department of Chemical Engineering, University of Illinois, Urbana, February 12, 1991.

"Propagation of disturbances in gas-liquid flows in pipes and packed beds", Department of Chemical Engineering, Ohio University, February 20, 1991.

"Propagation of disturbances in gas-liquid flows in pipes and packed beds", Department of Chemical Engineering, West Virginia University, March 6, 1991.

"Characterization of time-varying behavior in steady-state systems: gas-liquid flows in packed beds", Amoco Research Center, September 27, 1991. 
"Regular and irregular disturbances in gas-liquid flows", Department of Chemical Engineering, University of Virginia, April 23, 1992.

"Phenomenological understanding of gas-liquid stratified flows", Invited presentation at the Third International Workshop on Two-Phase Flow Fundamentals" Imperial College, London, June 15-19, 1992 (with T. J. Hanratty).

I. Research Presentations at Meetings

M. J. McCready and T. J. Hanratty, "A comparison of turbulent mass transfer at gas-liquid and solid-liquid interfaces", presented at the International Symposium on Gas-Transfer at Water Surfaces, Cornell University, June, 1983.

M. J. McCready, "Spectral behavior of capillary waves in gas-liquid flows", presented at the Annual Meeting of the American Institute of Chemical Engineers, Chicago, Illinois, November, 1985.

D. D. Back and M. J. McCready, "Numerical simulation of mass transfer at a sheared gas-liquid Interface" presented at the Annual Meeting of the American Institute of Chemical Engineers, Miami, Florida, November, 1986.

K. Bruno and M. J. McCready, "Theoretical considerations in the description of wave behavior in gas-liquid flows", presented at the Annual Meeting of the American Institute of Chemical Engineers, New York, November, 1987.

L. A. Jurman and M.J. McCready, "Waves at the interface of gas-liquid flows", presented at the annual meeting of the Fluid Mechanics division of the American Physical Society, Eugene, Oregon, November 1987.

M. J. McCready, L. A. Jurman and K. Bruno," Characterization of waves on thin, sheared liquid films", 2nd International Symposium on Annular and Dispersed Flows, Oxford, U.K. September 6, 1988.

M. J. McCready and L.A. Jurman, "Waves on thin, gas-sheared liquid films", annual meeting of the Fluid Mechanics division of the American Physical Society, Buffalo, New York, November 1988.

D. D. Back and M. J. McCready, "Effect of hydrodynamics and Schmidt number on turbulent mass transfer to a solid boundary", AIChE Annual meeting, Fall 1988.

K. Bruno and M. J. McCready, "Spectral behavior of waves in gas-liquid flows", AIChE Annual meeting, Fall 1988.

D. T. Leighton and M. J. McCready, "Shear-enhanced transport in oscillatory liquid membranes", AIChE Annual meeting, Fall, 1988.

M. J. McCready, "An alternative to the process design course", AIChE Annual meeting, Fall, 1988.

M. J. McCready, S. E. Deutsch and L. A. Jurman, "Modal wave interactions on airsheared liquid layers", annuai meeting of the Fluid Mechanics division of the American Physical Society, Palo Alto, CA, November 1989. 
M. Cheng, D. Enright, L. A. Jurman, H. -C. Chang and M. J. McCready, Nonlinear wave instabilities on sheared liquid layers: experiments and theory, AIChE Annual meeting, Fall, 1989.

M. Gupta and M. J. McCready, "Numerical and analytical study of interfacial mass transfer", AIChE Annual meeting, Fall, 1989.

M. J. McCready, L. A. Jurman, C. -A. Peng, and S. E. Deutsch, "Evolution of interfacial disturbances in horizontal gas-liquid flows", Eighth symposium on energy engineering sciences, Argonne, IL May, 1990.

M. J. McCready, M. Gupta, L. A. Jurman and K. Bruno, " Properties of small-scale waves in sheared gas-liquid flows", 2nd International Symposium on Gas Transfer at Water Surfaces, Minneapolis, MN, September, 1990.

S. E. Deutsch, L. A. Jurman and M. J. McCready, "Characterization of chaos in interfacial waves in an open flow system" AIChE Annual meeting, Fall, 1990.

C. -A. Peng, L. A. Jurman and M. J. McCready, "Characterization of solitary waves on thin, gas-sheared liquid layers" AIChE Annual meeting, Fall, 1990.

M. J. McCready, S. E. Deutsch, and L. A. Jurman, "Investigation of chaotic behavior of interfacial waves in an open flow system" annual meeting of the Fluid Mechanics division of the American Physical Society, Ithaca, NY, November 1990.

G. R. Shaub, M. J. McCready \& J. F. Brennecke, "Effects of jet characteristics on particles formed from the expansion of supercritical solutions", AIChE Annual meeting, Fall, 1991.

Th. Prokopiou, M. J. McCready \& H. -C. Chang, "Transitions to three dimensional waves on horizontal gas-sheared liquid films", AIChE Annual meeting, Fall, 1991.

M. Sangalli, M. J. McCready \& H. -C. Chang, "Spatial instability of two-phase stratified flow: theory and experiment", AIChE Annual meeting, Fall, 1991.

M. J. McCready "Disturbance origination and propagation in open flow systems", AIChE Annual meeting, Fall, 1991.

M. Sangalli, Th. Prokopiou, M. J. McCready \& H. -C. Chang,"Transitions in stratified two-phase flows: theory and experiments", Conference: Instabilities in multiphase flow, Rouen France, May 11-13, 1992.

J. A. Helwick, P. O. Dillon and M. J. McCready, "Time varying behavior of cocurrent gas-liquid flows in packed beds", 1st International conference on gas-liquid and gas-liquid-solid reactor engineering, Columbus OH, September 13-16, 1992.

M. Sangalli, Th. Prokopiou, M. J. McCready and H. -C. Chang, "Observed transitions in two-phase stratified gas-liquid flow", 1st International conference on gas-liquid and gas-liquid-solid reactor engineering, Columbus OH, September 13-16, 1992. 


\section{J. Patent}

"Separation device utilizing oscillated liquid membrane", D. T. Leighton and M. J. McCready, U.S. Patent No. 4,994,189. Issued February 19, 1991.

K. Selected Qther Professional Activities

Attended Summer School for Chemical Engineering Faculty, August 9-14, 1987.

CoChairman of session " Fundamental Research in Multiphase Flows", AIChE Ming. Washington, DC, November, 1988.

Organizer of sessions:" Fundamental Research in Multiphase Flows", AIChE Mtng. San Francisco, CA, November, 1989.

Consultant: vapor-liquid heat transfer for Dometic Corporation., 1989

Consultant: multiphase fluid mechanics for Amoco Oil Company.

Organizer of sessions:" Fundamental Research in Multiphase Flows", AIChE Mtng. Los Angeles, CA, November, 1991.

Refereed papers for: J. Fluid Mech., Nature, Phys. Fluids, Int. J. Mult. Flow., AIChE J., Chem. Eng. Sci., Multiphase Science and Technology, J. Colloid and Interfacial Science, J. Fluids Eng., Chem. Eng. Comm., Nuclear Engineering and Design.

\section{Eunded Activities}

\section{a. Research Grants}

"Characterization of turbulent mass transfer at a solid boundary", Funded by the Engineering Foundation, 1985, $\$ 17,000$.

"The effect of dominant waves on capillary waves in gas-liquid flows", Funded by the Petroleum Research Fund through the American Chemical Society, $1985, \$ 15,000$.

"An experimental investigation of coherent structures in turbulent wall flows", Funded by the Jesse Jones Faculty Research Fund, 1985, \$7,100.

"Simulation of heat or mass transfer across the interface of gas-sheared liquid films", National Center for Supercomputing Applications, 40 Hours of Cray time, 1988.

"Study of interfacial behavior in cocurrent gas-liquid flows", D.O.E., Basic Energy Sciences, 5/1/88 - 4/30/91, $\$ 176,912$.

"Experimental study of oscillatory liquid membranes", Army Research Office, 7/1/88$1 / 31 / 89, \$ 20,000$ (with D.T. Leighton).

"Stability of core-annular flow in lubricated transport of oil", ACS PRF, 9/1/88 - 8/31/91, $\$ 40,000$ (with H.-C. Chang).

"Capillary effects in gas-liquid flows", Chevron Research Company, $\$ 15,000$, $9 / 1 / 88-6 / 30 / 91$.

"Video imaging equipment for the study of multiphase flows", NSF, Engineering Equipment, (with D. T. Leighton), \$89,000 - 6/1/89-5/31/90. 
"Characterization of gas-liquid flows in packed beds" Amoco Oil Co., $\$ 75,000$ $1 / 90-12 / 92$.

"Evolution of flow disturbances in cocurrent gas-liquid flows" , D.O.E., Basic Energy Sciences, $\$ 162,000,5 / 1 / 91$ - 4/30/94.

"Study of disturbances in fluid-fluid flows in open and closed systems", NASA, (with H. -C. Chang and D. T. Leighton), $\$ 300,00012 / 1 / 92-11 / 30 / 95$.

\section{b. Education Grants}

"Lessons in Fluid Mechanics on the PC", CAChE Corporation, $\$ 1,500$ + equal matching by Notre Dame.

\section{Graduate Theses Directed}

Dwight D. Back, "Fundamental analyses of interphase mass transfer", -- Ph.D., 1988.

Kenneth Bruno, "A study of interfacial waves in gas-liquid flows", -- Ph.D., 1988.

Ching-An Peng, "The formation of solitary waves in horizontal, gas-liquid concurrent flows" -- M. S., 1990

Lorraine A. Jurman, "Interfacial waves on sheared, thin liquid films" -- Ph. D., 1990.

James Helwick, "Study of the time-varying behavior of gas-liquid concurrent flow in a packed bed" -- M. S., 1991.

Malini Gupta, "Fundamental analyses of heat and mass transfer in two-phase flows" -- Ph. D., 1991.

Theologos Prokopiou, "Nonlinear waves on liquid interfaces" -- Ph. D., 1992.

Paul Dillon, "A study of time-dependent gas-liquid flow in a packed bed using digital image analysis techniques" -- M. S. 1992.

\section{in progress}

William Kuru, "Turbulent transport of particles" -- Ph. D.

(with H.C. Chang)

Massimo Sangalli, "Evolution of sheared liquid layers" - Ph. D.

(with J. F. Brennecke)

Gina Shaub, "Study of precipitate particle growth from flashing supercritical fluids" -- Ph. D.

Edward Montalbano, "Flow of nonideal gases in high gradient situations" -- Ph. D. 

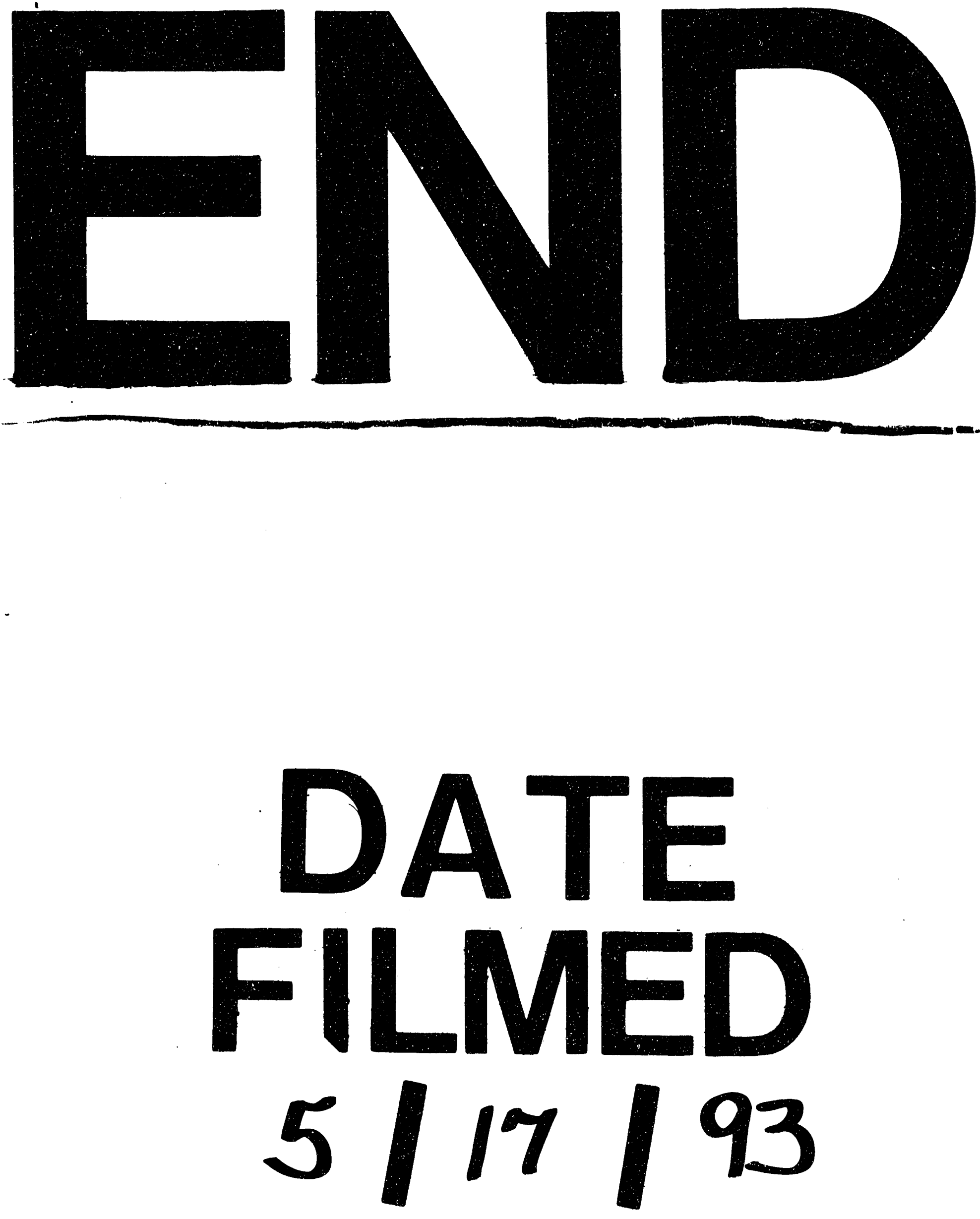


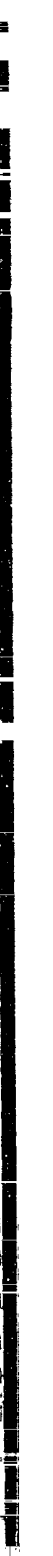

